\title{
The Use of Homonymy in Iraqi Colloquial Poetry
}

\author{
Tawfeeq AL-Ghazali \\ Director, Islamic University College, Najaf, Iraq
}

\begin{abstract}
This study is mainly concerned with the use of homonymy in Iraqi colloquial poetry as one of the technique in writing or spoken prose and verse. villagers in Iraq use this kind of arts to find their pleasure in talking after a hard day working in their farms.. I use my knowledge as Iraqi linguistic student to investigate homonym in English and ArabicIraqi colloquial poetry and compare between the two languages. To the best of my knowledge this study has not been tackled yet; therefore; the present study is an attempt to fill such a gap.
\end{abstract}

Keywords: Definition of homonymy, types of homonymy, polysemy, homograph, homonymy in Arabic.

\section{Introduction}

In fact, although homonymy is defined differently in English, yet in general, a word is similar in form with another word either in pronunciation (i.e.homophone) or in spelling (homograph). On the other hand, in Arabic, there is a general agreement that the homonym is an expression with one enunciation (or form) and more than one meaning. Actually, this phenomenon creates lexical and syntactic ambiguity in both languages. In addition, homonymy has its own features, specifications and forms in each language.

\section{Definitions of Homonymy in English}

Originally, the word "homonym" comes from the conjunction of the Greek prefix homo-, meaning "same", and suffix-⿳亠丷厂nymos, meaning "name". Thus, it refers totwo or more distinct concepts sharing the "same name" or signifier (Wikipedia2010: 1).

Lyons (1982: 72; and Yule 2006:107) define - dmonyms" as a term used in semantics for lexical items that are identical in spelling and pronunciation but have different meanings. Examples of homonyms are lie as in you have to lie down and lie in Don't lie, tell the truth. The above definition does not involve anything about homophones and homographs; in addition, it creates a problem with polysemy.

Hartmann and Stork (1976:105 al. ;Atihison 1993:52; and Fromkin et al 2003:71)

Agree that homonyms are different words with the same pronunciation that may or may not be identical in spelling. Thus, they give them a definition that is partially similar to that of homophones. On the other hand, Watkins et al. (2001:269) define it just like defining homophones, i.e., - ords that sound exactly like other words but have different spellings" in spite of the fact of not naming them homophones' in addition to "homonyms" as Fromkin et al 2003:71) do.

Gramley and Pätzold (1992:13) and Wikipedia (2010: 2), on the other hand, define homonymy as the existence of different lexemes that sound the same (homophones, e.g. days/daze) or are spelt the same (homographs, e.g.lead (guide)/lead(metal)) but have different meanings." In this way, they divide them into homophones and homographs. This is the definition that is adopted in this research. On a larger scope, homonymy is defined as a word that is identical in form with another word, either in sound (as a homophone) or in spelling (as a homograph), or both, but differs from it in meaning. For example, sale (an actor of selling something) and sail (to travel on water); bark (the skin of a tree) and bark (the sound of a dog); or pitch (throw)/pitch (tar).

\section{Types of Homonyms}

\section{A. Complete (full, absolute)}

Those are homonyms that have the same pronunciation and the same spelling i.e. the identity covers spoken and written forms. Classic examples are bank (embankment) and bank (place where money is kept) (Lyons 1982:72 and Allan 1986:150).

\section{B. Partial homonyms}

They are those where the identity covers a single medium, as in homophony and homography. Thus, homophones and homographs are considered partial homonyms (Crystal 2003:220). Watkins et al.(2001:269) different between homonyms and what they call near homonyms". According to them homonym share words that are "exactly" alike in pronunciation but differ in spelling and meaning, e.g. morning and mourning; there and their, while near homonyms do not sound exactly alike, e.g. except and accept; loose and lose.

\section{Word homonyms}

These are homonyms where all the forms of a paradigm and its collocational possibilities are identical. Thus, one does not get any indication of their belonging to one word or the other. Such homonyms are generally found in words belonging to the same part of speech. Examples are seal and seals (plural of seal which is an animal) and seal and seals (plural of seal which is an impression placed on thingsto legalize them). In addition, the possessive forms of these words, i.e, seal'sareidentical (Singh 1982: 24).

\section{Homonyms of word forms}

These are homonyms in which only few word forms are identical. Generally, the canonical forms in addition to some forms are alike and some others are not identical. For example lie that means not to tell the truth becomes lied in 


\section{International Journal of Science and Research (IJSR) \\ ISSN (Online): 2319-7064 \\ Index Copernicus Value (2013): 6.14 | Impact Factor (2014): 5.611}

the past and past participle while lie, that means to rest one's body, becomes layin the past (ibid.).

\section{E. Lexical Homonyms}

When the homonyms belong to the same part of speech, they are called lexical homonyms. The difference is only in their lexical meaning. They can be found under one entry in the dictionary (Singh 1982: 25). For example, trunk (part of anelephant) and trunk (a storage chest).

\section{F. Grammatical Homonyms}

When the difference between homonyms is not only confined to the lexical meaning but the grammatical types are also different, they are called grammatical homonyms. They are given separate entries in the dictionary. In these cases, the words have similar canonical form but different paradigms and structural patterns. Verbs occurring as transitive and intransitive or lexical units that occur as nouns, verbs, adjectives, etc. (e.g. cut (v.), cut (n.), cut (adj.)) are examples ofsuch homonyms (ibid.).

\section{Homonymy and Polysemy}

In semantic analysis, the theoretical distinction between homonymy and polysemy creates a problem that has captivated the attention of many linguists. Polysemy (pollyseamus in Latin) is defined roughly as the existence of onelexeme with many related meanings. The fact that polysemy is a property of single words is what differentiates it from homonymy in principle (Lyons 1982:146). For instance, the words neck, guard, music, and bachelor arepolysemous since each one of them appears in standard dictionaries of English asa single lexeme with several distinguishable meanings, whereas homonyms generally have separate dictionary entries often marked with superscripts. (Fromkin et al. 2003: 180).

The problem of how to draw the line between homonymy and polysemycan be solved by the recognition that the different senses of the word are related historically, i.e, they can be traced back to the same source, e.g. pupil (student)and pupil (of the eye) —although Yule (2006:107) mentions that homonyms are not historically related but have accidently become similar- or if one meaning can be derived from the other, i.e., there is a metaphorical connection between them and they are different uses of the same word, e.g. face (noun- front part of head) and face (noun- front part of clock). Leech (1976: 230) specifies the difference in the definitions of homonymy and polysemy in the following way: We can explain polysemy happily enough as the existence of more than one semantic specification for the same lexical item; and we can also define homonymy as the existence of more than one morphological specification sharing the same phonological or graphic form.

\section{Homonymy and Pun}

Pun is a witticism which relies for its effect on playing with the different meanings of a word, or bringing two words together with the similar form but different meanings; it is also called paronomasia (Crystal 2003:467).
Razzak et al. (1981: 123) define pun as the use of the same word (or two words similar in sound) in different senses for humorous purposes. For instance, you say you are studying trees. What branch of the subject are you specializing in? From the definitions above, homonymy is known as puns in literature because it creates much humour especially in literature. Writers like Shakespeareuse them frequently in their writings. Famous examples that are used by

Shakespeare are tail/tale, hole/whole, hoar/whore (Pyles 1971: 4).

\section{Homographs}

Palmer (1984:101, Allan 1986:151; Gramley and Pätzold 1991:13; Richards and Schmidt 2002:241) believe that homographs are words that are written in the same way but are pronounced differently and have different meanings. Well known examples of homographs are lead/led/ (metal) and lead/li:d/ (guide).Sometimes, the term homograph' is used interchangeably with the term homonym" as indicated by Richards and Schmidt (2002:241). However, homographs and homophones are considered part of homonymy. Another definition is that homograph is a term used in semantic analysis to indicate lexemes that are written alike but may or may not be pronounced similarly and have different meanings (Pyles 1971:4 and Wikipedia 2010: 2).

Lyons (1982:71) and Crystal (2003:220) illustrate that homographs are words that share the same spelling but differ in meaning. For instance, wind(blowing) and wind (verb- a clock). This definition ignores the element of pronunciation. Thus, problems of ambiguity may occur between homographs and polysems. In writing, homograph is defined as one kind of writing system or spelling in which there is one-to-one correspondence between graphic signs and speech sounds. Examples of such homographic systems are the phonetic transcription, or the alphabets of some languages that have a phonetic alphabet. As such, the opposite to the term homograph" is heterogrophy'. The spelling system of languages like English or French are examples of heterotrophic writing systems(Hartmann and Stork 1976:105 and Crystal 2003:220).

\section{Homographs and Heteronyms}

The term heteronym' is used for words that are identical in spelling but different in pronunciation and meaning. Examples of heteronyms are dove $/ \mathrm{d} \Lambda \mathrm{v} /$ (a bird) and dove /douv/ (the past tense of dive)wind/wind/ (noun- air that moves quickly) and wind/waind/ (verb- to twist something); $\boldsymbol{b o w} / \mathrm{bau} /$ (to bend) bow /bou/ (a weapon used for shooting arrows), and hundreds of others (Fromkinetal. 2003: 180).

Hence, heteronymy equals homography according to the first definition of Hence, heteronym my equals homography according to the first definition of homography; or heteronymy is part of homography following the second definition in which all heteronyms are homographs but not the reverse. 


\section{International Journal of Science and Research (IJSR) \\ ISSN (Online): 2319-7064 \\ Index Copernicus Value (2013): 6.14 | Impact Factor (2014): 5.611}

\section{Homophones}

Many linguists agree that homophones are two or more words that sound alikebut are written differently and have different meanings. Examples ofhomophones are threw/through, sight/site, and rite/right/write/wright (Palmer1984:101; Lass 1998:29; Richards and Schmidt 2002:241; and Crystal 2003:221). Thus, homophones are deemed to be part of homonymy, the other part beinghomographs.

\section{Homonymy and Ambiguity}

Homonymic clash (sometimes called homophonic clash or homonymic conflict) isa term used to refer to the ambiguity arising from homonyms because of thesimilarity in spelling and/or enunciation. A very famous example is the sentenceI'll meet you by the bank, which may mean I'll meet you by the financialinstitution' or I'll meet you by the riverside". Therefore, the word bank thatmeans embankment and the word bank that means riverside are the causebehind this ambiguity (Fromkin et al. 2003:180). Another example that is afamous riddle is the following (Hartmann and Stork 1976:105):

Accordingly, it is believed that ambiguity can be solved in speech becausenormally in context one's intention when using homonymous words is quiteunambiguous since additional context can help to disambiguate the sentence(Lass 1998:29 and Riggs 1999:6).

Hence, the sentence I'll meet you by the bank, can be clarified in the following way:

1) I'll meet you by the bank, in front of the automated teller machine.

2) I'll meet you by the bank. We can go skinny-dipping. (Fromkin et al. 2003:180)

In addition to the problem of ambiguity many spelling problems may occur. Thus, glossary of usage is found in some books to identify and distinguish between many common homonyms (Watkins et al. 2001:296).

\section{Definitions of homonymy in Arabic}

Homonymy in Arabic is known as (Al-moStarakallafdi) or (al- motajanisallafdi) or (al-motaSabihallafdi), that means the similarity in pronunciation.

(Al-Khuli2001:141 ; and Mansur 2009:1) define homonymy as a word or a sentence that has one articulation (or form) and more than one meaning. For example, the word (sin) has one articulation whether it means age or tooth; and (deqeeq) which means flour,

\section{Types of Homonyms in Arabic}

Homonyms in Arabic can be divided into the following types:

A. Homonymic words that have two meanings. For example, (qadam) meansfoot (part of body) or(unit of length).
Another example is (lisaan) means tongue (organ of body) and (language) (Al-Khuli;2001: 143-4).

B. Homonymic words that have multiple meanings. Such words in Arabic are :(fusool) that has the meanings (chapters of a book), (seasons of year), (semesters inschool), (acts of a play), etc.

C. Homonymic words that have a relation in meaning. For instance, in Arabic, the word(yed)may mean part of body and power; and the word (dira?) has the meanings organ in body and unit of measurement. This kind is actually known as polysemy in English (Al Khuli 2001:143 and Umer 1982:63-4).

D. Homonymic words that have no relation in meaning. The word (qirin) may mean the horns of an animal or a hundred years. (Al Khuli 2001: 143).

E. A unique kind of homonymy in which the pronunciation is the same while the writing is different, i.e., homophony, is found in Arabic. Instances of this type are (lyehya) means (to live) and (yehya) (a name of a person) another example is

Ex..Ra'ytu al-nasaqeddehabuilamen ?indahodehabu I saw the people had gone to whom has gold

In which (dahabu) means went" and (dahabu) is gold. (NasirAlDeen 2010: 3).

\section{Homonymy and Synonymy}

Actually, homonymy is different from synonymy although both are relationsbetween words. Generally, homonymy is a word that has more than onemeaning, whereas synonymy denotes two or more words that have approximately the same meaning (Al Dersoni 2010: 1).

For instance, thehomonymic word (xal) means either uncle (mother's brother) or mole (in thebody), to think or doubt something, or clouds (Al-Dhamin 1990: 66).

\section{Instances ofsynonymous words are:}

Qara'a, tala $=$ to read

aqsama, Halafa = to swear (Yousif 2009:1 )

ijood, saxa', karam, = generosity

yera, yobsr, yo $?$ ayin, yoSahid, $=$ to see

sana, Hol, ?aam , = year

masroor,faraH, mostabSir, = happy (Al Dersoni 2010: 1)

\section{Homonymy and Ambiguity}

In Arabic, there are two sorts of ambiguity - lexical and syntactic. In one hand, lexical ambiguity occurs because the sentence contains a word which has morethan one meaning that causes the ambiguity. The sentences: (Al Khuli 2001: 148-150) For instance, the word(Daraba ) has many senses in differentcontexts. Consider the following sentences (Ownn 2005:151-2):

ZaydunDaraba al-lissa $=$ to punish

DarabaAllahumathalan $=$ to mention

Darabalahuqubatan $=$ to erect

\section{Volume 5 Issue 2, February 2016}


Darabaalumlah $=$ to coin

Darabalahumaw? $\mathrm{id}=$ to assign

Daraba fi alard $=$ to seek or go about

Darabaxamsah fi sittah = to multiply

Darabaaxmasbasdas $=$ to be confused

\section{Data analysis from Iraqi colloquial poetry.}

\section{Yerahaay:}

abifrukCanlemaadmeCenyeraHaay

Want rub until bloody my palms

"I want to rub my palms until the blood comes out."

Bsababkil-HeentillaCmenyeraHaay

Because every time painful my wounds

"Because every time my wounds are painful"

Ana kilmenniDerSexs-y yera-Haay

I everyone looks to body- my see-alive

Everyone looks to my body he sees it a live"

Anamayyitbsababfurga-k iliya

I was dead because ofseparation your to me

I was dead because of your separation.

In example above the word "ye-raHa-ay"in first line refers to the speaker's palms and by adding the prefix (ye) almoxaDab (addressee) and the suffix (a-y)(a- for dual and $\mathbf{y}-$ for possessive pronoun my) the poet created partial homonym. The second line the word "yeraHaay" refers to the poet's wounds and originally, the word's form is jirahaay" but according to the speaker's dialect which is related to the southern part of Iraq (ji) became (ye) . in the third line the word "yeraHaay" consists of two words ("yera" which means" see" and the word "Haay" which means "alive")and contrastive with the word "mayyit" it iscalled"antonomy"these words together and the synonyms wards "yera" and "niDer" which mean "see" in Englishallcreate the pun (humor) and the homonyms to the texts.

\section{Karaha :}

il-dami?Nehr-an bi-xdood-i karaha

The-tears 2 rivers in cheek- mydigged

"The tearsdigged two rivers in my cheeks."

Habeeb-I silabmin ?en -i karaha

Beloved- my stole from eye- my sleep

My beloved stole the sleep from my eye."

Mehabta-k leishilisaratkaraha

Love- your why to mebecamehate

\section{Why your love became hate to me"}

In the example (2) above the homonym word "karaha" occurs in different meanings, in the first line means "digged" and the second line means "sleep" and in the third line means "hate" which is contrasted with the word "mehaba" which means love and these two words called antonymy.

\section{Conclusions}

The research reached to this conclusions

1) Originally, in English the word homonymy is divided into homophony and homography, whereas this term is translated as - mStaraklefdi" in Arabic which refers to a word that has one articulation and more than one meaning.

2) The definition of homonymy in Arabic is similar to the definition of polysemy in English, i.e. they are considered to be one.

3) The difference between them is that homonyms in Arabic may have a relation or no relation in their meanings, while polysems in English have a relation in meaning. Hence, the two types of homonyms, i.e., those that have a relation in meaning and those that do not, are not found in English.

4) Some Arab linguists believe that homonymy does not exist in Arabic because they think that homonymic words have one real meaning while the rest are metaphorical.

5) Homonymy is defined differently in English while in Arabic there is an agreement among linguists on its definition.

6) The types of homonyms in English are complete, partial, word homonyms, homonyms of words form, lexical homonyms, and grammatical homonyms, while the types of homonymy in Arabic are those that have only two meanings, multiple meanings, a relation in meaning no relation in meaning, homonyms created because of shift in application, homonyms created due to shift in articulation, and those that have identical present and past participle.

7) Homonymy is used heavily by poets and writers in Arabic, since it has a relation to some of the types of pun and allusion metaphor in which it is used for purposes like creating humour, musical effect, attracting attention, aesthetical purposes, playing on words to create beauty etc.

8) In both languages, the phenomenon of homonymy creates ambiguity that is lexical and syntactic.

\section{References}

[1] Allan, K. (1986). Linguistic Meaning. Vol.1. London: Routeledge and Kegan Paul.

[2] Atichison, J. (1993). Teach Yourself Linguistics. London: Hoddor and Stoughton.

[3] Crystal, D. (2003). A Dictionary of Linguistics and Phonetics. 5th ed. Oxford: Blackwell Publishers Ltd.

[4] Fromkin, V.; Rodman, R.; and Hyams, N. (2003).An Introduction to Language. $7^{\text {th }}$ ed. USA: Heinle, a part of Thomson Corporation.

[5] Gramley, S. and Pätzold, K. (1992).A Survey of Modern English. London: Routledge.

[6] Hartmann, R. and Stork, F. C. (1976).Dictionary of Language and Linguistics. London: Applied Science Publishers Limited.

[7] Leech, G. N. (1976). Semantics.Harmondsworth, Middlesex: Penguin Books.

[8] Literary Dictionary. (2004). The Concise Oxford Dictionary of Literary Terms. Chris Baldick.

[9] Lyons J. (1982).Language and Linguistics. Cambridge: Cambridge University Press. 
[10] Oxford Wordpower. (2000). Oxford: Oxford University Press.

[11]Palmer, F. R. (1984). Semantics. Cambridge: Cambridge University Press.

[12] Pyles, Thomas. (1971). The Origin and Development of the English Language. New York: Harcourt Brace Jovanovich, Inc.

[13] Razzaq, F. A. and Helen Al-Hassan.(1981). College composition. Baghdad, Iraq: The Institute for the Development of English Language Teaching in Iraq.

[14] Richards, J.C. and Richard Schmidt. (2002). Longman Dictionary of Language Teaching and Applied Linguistics. Essex, England: Pearson Education Limited.

[15]Riggs, F.W. 1999. Homonyms, Heteronyms and Allonyms: A Semantic/Onomantic Puzzle. www2.hawaii.edu/fredr/homonymy.htm

[16] Singh, R. A. (1982). An Introduction to Lexicography: Meaning and its Relationship to Form. www.ciilebooks.net/html/lexico/link6.htm

[17] Watkins, F. C.; Dillingham, W. B.; and Hiers, J. (2001).Practical English Handbook. 11th ed. Boston: Houghton Mifflin Company.

[18] Wikipedia.(2010). "Homonymy". en.wikipedia.org/wiki/User:Homograph

[19] Yule, G. (2006). The Study of Language. 3rd ed. Cambridge: Cambridge University Press. 